\title{
Alkaloids in White Lupin and Their Effects on Symbiotic N Fixation
}

\author{
Kristina D. Staples ${ }^{1}$, Anwar A. Hamama ${ }^{1}$, Regina Knight-Mason ${ }^{2} \&$ Harbans L. Bhardwaj ${ }^{1}$ \\ ${ }^{1}$ Agricultural Research Station, Virginia State University, Petersburg, VA, USA \\ ${ }^{2}$ Department of Biology, Virginia State University, Petersburg, VA, USA \\ Correspondence: Harbans L. Bhardwaj, Agricultural Research Station, Virginia State University, P.O. Box 9061, \\ Petersburg, VA 23806, USA. Tel: 1-804-524-6723. E-mail: hbhardwaj@vsu.edu
}

Received: March 22, $2017 \quad$ Accepted: April 23, $2017 \quad$ Online Published: May 15, 2017

doi:10.5539/jas.v9n6p13 URL: https://doi.org/10.5539/jas.v9n6p13

This work is a contribution of Virginia State University, Agricultural Research Station. The use of any trade names or vendors does not imply approval to the exclusion of other products or vendors that may also be suitable. These studies were conducted as a part of MS Degree thesis research of Kristina Staples.

\begin{abstract}
Seeds of white lupin (Lupinus albus L.), known to potentially fix 150 to $200 \mathrm{~kg} / \mathrm{ha} \mathrm{N}$ via Symbiotic N Fixation (SNF), are classified as sweet or bitter based on their alkaloid contents: sweet lupins contain very low whereas bitter lupins contain high contents of alkaloids. However, precise information about effects of alkaloid content on SNF is not very well unknown. Experiments were conducted to determine if alkaloid content in the seed is related to that in other plant tissue such as leaves and pod shells, characterization of relationship between alkaloid concentration and SNF, and to study variation among 126 white lupin accessions for concentration of alkaloids. In the first experiment, the Dragendorff test, a colorimetric test, was used to categorize field-grown lupin lines into 6 categories: $0,1,2,3,4$, and 5 with 0 representing sweet and 5 representing extreme bitterness with bitterness increasing from 0 to 5. In the second experiment, ten lupin lines differing in their Dragendorff score from 0 to four were inoculated with seven bradyrhizobial strains and studied for SNF in a greenhouse. A numerical scale from 0 to 4 with 1 representing absence of nodules and 4 representing many functional nodules was used as a measure of SNF. In the third experiment, concentrations of alkaloids (Dragendorff scores), oil, and protein were studied in 126 accessions.

Results indicated that all progenies with Dragendorff score of 1 for the seeds also had the same score for leaves and pod shells. However, this was not true for other progenies. In the case of progenies with Dragendorff scores of $0,2,3$, or 4 in the seed, the Dragendorff scores for leaves and pod shells were above and below the seed scores indicating existence of variation for alkaloids in various tissues of the lupin plant. Alkaloid content also had significant effects on root nodulation. The interaction between alkaloid categories and bradyrhizobial strains was non-significant. The root nodulation score for lupin lines in alkaloid categories 0,3 , and 4 were similar, indicating that the same bradyrhizobial strain could be used to effectively inoculate sweet and bitter white lupin lines. The root nodulation induced by the seven bradyrhizobial strains were statistically different. It was observed that S96-A15, S96-A19, and S96-B9 were more efficient bradyrhizobial strains whereas S96-A5 was observed to be less efficient for root nodulation. Significant variation existed among 126 white lupin accessions for Dragendorff score and concentrations of oil and protein. The alkaloid content did not affect oil content in the seed, however, alkaloid content significantly affected protein content. The results indicated that bitter seeds had higher protein content.
\end{abstract}

Keywords: Lupinus albus, root nodulation, dragendorff test, bradyrhizobium, germplasm, protein concentration, oil concentration.

\section{Introduction}

\subsection{Problem}

The use of nitrogen $(\mathrm{N})$ fertilizers has been an enigma for modern agriculture: on one hand, their use has been linked to environmental pollution, while on the other hand they have contributed to yield increases (Drinkwater et al., 1998). Alternatives to the use of inorganic fertilizers, especially $\mathrm{N}$ fertilizers, are needed to reduce cost of 
production and pollution of water resources. A suitable grain legume crop can provide an alternate to use of inorganic $\mathrm{N}$ fertilizers through Symbiotic N Fixation (SNF).

\subsection{Background}

Earlier research, conducted in Virginia, has demonstrated the existence if specificity between host white lupin (Lupinus albus L.) plant and Bradyrhizobium strain (Robinson et al., 2000). Additional studies have indicated that white lupin has tremendous potential and can be successfully used as a legume cover crop to support production of summer crops such as sweet corn and muskmelon (Bhardwaj, 2006). Currently there is a lack of precise information regarding effects of alkaloid content on white lupin $\times$ Bradyrhizobium strain interaction.

Lupin seeds vary in their alkaloid contents and are classified as bitter (High alkaloid content) and sweet (Lack of alkaloids or very low concentration of alkaloids). Lupin seeds are generally classified as "sweet" or "bitter" depending upon the content of alkaloids which can vary from $0.01 \%$ to $4 \%$ (Allen, 1998). Sweet lupin have potential as food whereas bitter lupin have potential as a green manure where alkaloids can be used to naturally control/manage various soil pathogens. The bitter seeds contain quinolizidine alkaloids such as lupanine, lupinine, and sparteine (Wink, 1993). The presences of these alkaloids limit the use of lupin seeds as food and feed (Muzquiz et al., 1994). The Australian standard is $0.02 \%$ as the upper alkaloid content limit for sweet lupin (Cowlings et al., 1998). Before the development of sweet lupins, the bitter lupin seeds were debittered by soaking in running water and cooking/toasting (Hill, 1977; Aguilera \& Trier, 1978). The lupin breeding work of Sengbusch in Germany during 1928-1929 laid the foundation for development of sweet lupin cultivars. Currently, sweet cultivars are available in all four lupin species that are being used as agricultural crops in the world (Cowling et al., 1998). However, it is well established that bitter lupin have a distinct advantage over sweet lupin plants relative to winter survival, seed yield, and seed weight (Cowling et al., 1998) and competition with weeds (Wink \& Twardowski, 1992; Wink, 1985). The alkaloids are known to confer an advantage to bitter lupin plants due to their pesticidal effects on micro-organisms and insect-pests (Gladstones, 1998; Wink, 1993). It has been suggested that breeding lupin for sweet seed and bitter leaves and stems for protection from insect-pests and diseases should be a goal of most lupin breeding programs (Wink, 1993).

Earlier research, conducted in Virginia, has demonstrated the existence if specificity between host white lupin (Lupinus albus L.). Since utilization of lupin in a sustainable system may require production of sweet lupin for food/feed uses and production of bitter lupin for use as green manure crop, it is important to study SNF in white lupin. If successful, lupin could be used in sustainable and conventional agriculture to reduce/eliminate the use of inorganic $\mathrm{N}$ fertilizers, to cut down on excessive $\mathrm{N}$ use, and could be used as food and/or feed. Sweet lupin could be used as food or feed and bitter lupin could be used as green manure due to SNF and potential use of alkaloids as a natural pesticide. Additionally, if alkaloid content is not related to biological $\mathrm{N}$ fixation then the same inoculum could be used for both sweet and bitter lupin and if alkaloid content is determined to affect SNF then strategies could be developed to utilize lupin. Earlier research, conducted in Virginia, has demonstrated the existence if specificity between host white lupin (Lupinus albus L.).

\subsection{Solution}

The objectives of these studies were to characterize the alkaloid content in different plant tissues; Characterize the effects of alkaloid contents on nodulation on roots; Characterize the interaction between lupin lines differing in their alkaloid content and bradyrhizobial strains; and Characterize the variation among white lupin germplasm in the USDA-ARS collection.

\section{Materials and Methods}

\subsection{Experimental Details}

\subsubsection{Experiment-1}

1) Characterization of alkaloid content in different plant tissues:

In the Lupin Breeding Program of Virginia State University, 1046 advance-generation lines were planted in the field at the Randolph Farm of Virginia State University on September 26, 2003. Each line was planted as a single $3 \mathrm{~m}$ long row. The rows spaced at $75 \mathrm{~cm}$ apart. Based on visual observations related to growth and vigor, approximately 300 lines were characterized as winter-hardy under Virginia's agro-climatic conditions during February-March of 2004. From this group, 97 lines were selected for inclusion in the present study. These 97 lines constituted the plant material for this study. Details of these lines, relative to alkaloid concentration, follow: 


\begin{tabular}{ll}
\hline Dragendorff score & Number of lines \\
\hline 0 & 3 (Sweet) \\
1 & 6 \\
2 & 19 \\
3 & 36 \\
4 & 33 (Bitter) \\
\hline
\end{tabular}

Bulk leaf and pod samples from these lines were harvested in March to April of 2004. The pods were separated into seeds and pod shells. The sap from leaves, pod shells, and green seeds was squeezed on Dragendorff paper and the materials were characterized for their alkaloid content.

\subsubsection{Expperiment-2}

2) Characterization of effects of alkaloid contents on nodulation on roots and interaction between lupin lines differing in their alkaloid content and bradyrhizobial strains:

Ten selected lines from the 97 identified under Experiment-1 were used in this experiment along with 7 bradyrhizobial strains. Details of these lines follow:

\begin{tabular}{lll}
\hline Number & Line & Alkaloid Category \\
\hline 1 & VSL-184X & 4 \\
2 & VSL-520X & 4 \\
3 & VSL-571X & 3 \\
4 & VSL-573X & 2 \\
5 & VSL-581X & 1 \\
6 & VSL-585X & 1 \\
7 & VSL-603X & 3 \\
8 & VSL-618X & 2 \\
9 & Lucyanne & 0 \\
10 & Ludet & 0 \\
\hline
\end{tabular}

The following seven bradirhyzobial strains were provided for these studies by EMD Crop BioScience, Inc. (Now Novozymes BioAg, Inc., Milwaukee, Wisconsin USA 53209): Lupine - Strain 96A5; Lupine - Strain 96A15; Lupine - Strain 96A18; Lupine - Strain 96A19; Lupine - Strain 96A20; Lupine - Strain 96A22; and Lupine Strain 96B9.

The ten lupin lines and seven bradyrhizobial strains were evaluated in the greenhouse during 2005. The experimental design used was a Completely Random Design with four replications. Each combination of lupin line and bradyrhizobial strain was planted in four different pots (Four replications) on February 1, 2005. Thirty $\mathrm{cm}$ tall plastic pots were filled with moistened planting material ( 1 sterilized vermiculite: 1 filtered sand on a v/v basis). Two seeds, dipped in the liquid solution of the inoculum, were placed in each pot in a hole about $3 \mathrm{~cm}$ deep and were immediately covered with dry planting material and were watered liberally. All pots were watered every other day until harvesting. All pots were watered every other day until harvesting. The lupin plants in all pots were gently removed from the pots on March 11, 2005 and were washed with a gentle stream of tap water to dislodge the planting material from the roots. Nodulation data from all roots were recorded based on a quantitative scale of 0 to 4 with 1 representing absence of nodules and 4 approximately representing ten functional nodules. The scores of 1 through 4 represented progressively increasing nodule numbers.

\subsubsection{Experiment-3}

3) Characterize the variation among white lupin germplasm in the USDA-ARS collection:

For this study, we used 126 accessions from the white lupin collection of USDA-ARS, maintained at Pullman, Washington. Five to ten seeds of each accession were used to classify these accessions for their alkaloid content by using the Dragendorff test and to determine the oil and crude protein contents. Crude protein was determined by multiplying total $\mathrm{N}$ content by a factor of 6.25 . The $\mathrm{N}$ content of lupin seeds was determined by A\&L Laboratories (Now: Waypoint Analytical - Virginia, Richmond, VA 23237 USA). The oil was extracted from $1 \mathrm{~g}$ of ground seed at room temperature by homogenization (15) for $2 \mathrm{~min}$ in $10 \mathrm{~mL}$ hexane/isopropanol $(3: 2, \mathrm{v} / \mathrm{v})$ 
with a Biospec Model 985-370 Tissue Homogenizer (Biospec Products, Inc. Racine, WI, USA) and centrifuged at 4000 RCF (Relative Centrifugal Force) for $5 \mathrm{~min}$. The oil extraction was repeated three times for each sample to ensure full oil recovery and the three extractions were combined. The hexane-lipid layer was washed and separated from the combined extract by shaking and centrifugation with $10 \mathrm{~mL}$ of $1 \% \mathrm{CaCl}_{2}$ and $1 \% \mathrm{NaCl}$ in $50 \%$ methanol. The washing procedure was repeated and the purified lipid layer was removed by aspiration and dried over anhydrous $\mathrm{Na}_{2} \mathrm{SO}_{4}$. The oil percentage $(\mathrm{g} / 100 \mathrm{~g}$ dry basis) was determined gravimetrically after drying under vacuum at $40{ }^{\circ} \mathrm{C}$ and stored under $\mathrm{N}_{2}$ at $10{ }^{\circ} \mathrm{C}$ until analysis.

\subsection{Data Analysis}

All data were analyzed using the Analysis of Variance procedure in version 9.4 of SAS (2012). The means were compared using Fisher's Protected Least Significant Difference at a 5\% level of significance. The Pearson Correlation Coefficients were calculated to determine the relationships between various pairs of traits.

\section{Results and Discussion}

\subsection{Characterization of Alkaloid Content in Different Plant Tissues}

The Dragendorff test of the leaves revealed that 97 white lupin can be classified into five groups. Three progenies had a zero Dragendorff score indicating that these could be classified as sweet. On the other extreme, we did not find any progeny with the Dragendorff score of 5 indicating bitterness but 33 progenies were assigned a Dragendorff score of 4 indicating comparative higher bitterness. The relationships between alkaloid contents in leaves and green seeds are presented in Table 1.

Table 1. Distribution of white lupin progenies based on alkaloid category of leaves within alkaloid categories of green seed from plants grown at Petersburg, Virginia during 2003-04 season

\begin{tabular}{lllllll}
\hline \multirow{2}{*}{ Seed category } & \multicolumn{6}{c}{ Number of progenies within each seed alkaloid category for leaves. } \\
\cline { 2 - 6 } & 0 & 1 & 2 & 3 & 4 & Total \\
\hline 0 & 2 & 1 & 0 & 0 & 0 & 3 \\
1 & 0 & 6 & 0 & 0 & 0 & 6 \\
2 & 0 & 14 & 3 & 2 & 0 & 19 \\
3 & 0 & 12 & 3 & 21 & 0 & 36 \\
4 & 0 & 2 & 3 & 28 & 0 & 33 \\
\hline
\end{tabular}

Note. These results were previously reported in Proceedings of International Lupin Conference held in Guadalajara, Mexico from September 14-18, 2005 (Bhardwaj et al., 2005).

The relationships between alkaloid contents in the green seeds and the leaves are presented in Table 1. Within the group of progenies identified to be sweet (Dragendorff category 0), 2 progenies were classified as sweet based on scores from leaves and one was classified as category 1 . Within the group of progenies with seed Dragendorff category 1, all six progenies were identified also as category 1, based on leaves. Within the group of progenies with seed Dragendorff category 2, the 19 progenies were distributed into three categories of 1,2 , and 3, based on leaves $(14,3$, and 2 progenies, respectively). Within the group of progenies with seed Dragendorff category 3 , the 36 progenies were distributed into three categories of 1,2 , and 3, based on leaves $(12,3$, and 21 progenies, respectively). Similarly, within the group of progenies with seed Dragendorff category 4 , the 33 progenies were distributed into three categories of 1,2 , and 3 , based on leaves $(2,3$, and 28 progenies, respectively). These results indicate that variation existed among lupin lines for alkaloids in leaves within each category based on alkaloid content in the seed except for seed category 1 when no variation existed among six lines for alkaloid content of leaves.

The Dragendorff test indicated that 97 white lupin lines can be characterized into five groups based on alkaloid concentration in pod shells (Table 2). However, distribution based on alkaloids in leaves and pod shells was identical for lines with seed alkaloid categories 0 and 1. Within the group of progenies with seed Dragendorff category 2 , the 19 progenies were distributed into three categories of 1,2 , and 3 , based on pod shells $(5,12$, and 2 progenies, respectively). Within the group of progenies with seed Dragendorff category 3, the 36 progenies were distributed into three categories of 1,2 , and 3 , based on pod shells $(1,3$, and 32 progenies, respectively). Within the group of progenies with seed Dragendorff category of 4, the 33 progenies were distributed into three categories of $2,3,4$, based on pod shells $(1,25$, and 6 progenies, respectively). These results indicate that 
variation existed among lupin lines for alkaloids in pod shells within each category based on alkaloid content in the seed except for seed category 1 when no variation existed among six lines for alkaloid content of pod shells.

Table 2. Distribution of white lupin progenies based on alkaloid category of pod shells within alkaloid categories of green seed from plants grown at Petersburg, Virginia during 2003-04 season

\begin{tabular}{lllllll}
\hline \multirow{2}{*}{ Seed category } & \multicolumn{5}{c}{ Number of progenies within each seed alkaloid category for pod shells. } \\
\cline { 2 - 7 } & 0 & 1 & 2 & 3 & 4 & Total \\
\hline 0 & 2 & 1 & 0 & 0 & 0 & 3 \\
1 & 0 & 6 & 0 & 0 & 0 & 6 \\
2 & 0 & 5 & 12 & 2 & 0 & 19 \\
3 & 0 & 1 & 3 & 32 & 0 & 36 \\
4 & 0 & 0 & 1 & 25 & 6 & 33 \\
\hline
\end{tabular}

Note. These results were previously reported in Proceedings of International Lupin Conference held in Guadalajara, Mexico from September 14-18, 2005 (Bhardwaj et al., 2005).

The analysis of data indicated that the correlation between alkaloids in the leaves and green seeds was +0.68 ; that between leaves and pod shells was +0.70 ; and that between pod shells and green seed was +0.83 . All these correlations were significant at the $1 \%$ level.

The results from this study indicate that it may be possible to develop lupin lines with sweet or bitter seeds each combined individually with differing alkaloid content in other plant tissues. It was interesting to note that there was a lack of variation for alkaloid content in the leaves or pod shells in category 1 based on seed alkaloids. This observation needs further evaluation. We did not record any progeny with the Dragendorff score 5 which would classify the seeds as extremely bitter. However, it may be possible to characterize some lines in this category based on analysis of mature seeds. Our studies did not include mature seeds. The significance of these observations lies in the fact that it may be possible to develop lupin lines that have sweet seeds for use as food or feed whereas the remaining plant tissue contains high levels of alkaloids to make it suitable as a soil amendment to manage harmful micro-organisms.

\subsection{Characterization of Effects of Alkaloid Contents on Nodulation on Roots and Interaction between Lupin Lines Differing in Their Alkaloid Content and Bradyrhizobial Strains}

The analysis of variance (Table 3) indicated that lupin lines and bradyrhizobial strains had significant effects on root nodulation. The interaction between lupin lines and bradyrhizobial strains was non-significant indicating that means of lupin lines averaged over all bradyrhizobial strains and the means of bradyrhizobial strains averaged over all lupin lines could be compared. The root nodulation score for ten lupin lines (Table 4) ranged from 0.25 (VSL-585) to 1.43 (VSL-184). The root nodulation score for seven bradyrhizobial strains (Table 5) varied from 0.03 (S96-A5) to 1.57 (S96-A19). This experiment identified the S96-A19 bradyrhizobial strain to the most efficient nodulator.

Table 3. Analysis of variance for root nodulation in ten white lupin lines inoculated with seven bradyrhizobial strains in the greenhouse during 2005 at Petersburg, Virginia

\begin{tabular}{ll}
\hline Source of variation & Mean Squares \\
\hline Lupin lines & $4.03^{* *}$ \\
Bradyrhizobial strains & $14.58^{* *}$ \\
Interaction & 0.87 \\
Residual error & 0.88 \\
\hline
\end{tabular}

Note. *, **: Significant at 5 and 1\% level of significance, respectively. The root nodulation score ranged from 0 to 5 numerical scale with 0 indicating lack of root nodulation and 5 indicating maximum nodulation. 
Table 4. Root nodulation score of ten white lupin lines inoculated with seven bradyrhizobial strains in the greenhouse during 2005 at Petersburg, Virginia

\begin{tabular}{lll}
\hline Lupin line & Alkaloid category & Root nodulation score \\
\hline VSL-184 & 4 & $1.43 \mathrm{a}^{*}$ \\
VSL-603 & 3 & $1.18 \mathrm{ab}$ \\
Ludet & 0 & $0.96 \mathrm{abc}$ \\
VSL-571 & 3 & $0.93 \mathrm{abc}$ \\
VSL-618 & 2 & $0.79 \mathrm{bcd}$ \\
VSL-520 & 4 & $0.75 \mathrm{bcd}$ \\
Lucyanne & 0 & $0.48 \mathrm{~cd}$ \\
VSL-573 & 2 & $0.43 \mathrm{~cd}$ \\
VSL-581 & 1 & $0.39 \mathrm{~cd}$ \\
VSL-585 & 1 & $0.25 \mathrm{~d}$ \\
\hline
\end{tabular}

Note. * Means followed by the same letters within columns and main factors were not different according to Duncan's Multiple Range Test at 5\% level of significance. The root nodulation score ranged from 0 to 5 numerical scale with 0 indicating lack of root nodulation and 5 indicating maximum nodulation. These results were previously reported in Proceedings of International Lupin Conference held in Guadalajara, Mexico from September 14-18, 2005 (Bhardwaj et al., 2005).

Table 5. Root nodulation score of seven bradyrhizobial strains with ten white lupin lines in the greenhouse during 2005 at Petersburg, Virginia

\begin{tabular}{ll}
\hline Bradyrhizobial strain & Root nodulation score \\
\hline S96-A19 & $1.57 \mathrm{a}^{\dagger}$ \\
S96-A15 & $1.35 \mathrm{a}$ \\
S96-B9 & $1.18 \mathrm{a}$ \\
S96-A22 & $0.62 \mathrm{~b}$ \\
S96-A18 & $0.31 \mathrm{bc}$ \\
S96-A20 & $0.17 \mathrm{bc}$ \\
S96-A5 & $0.03 \mathrm{c}$ \\
\hline
\end{tabular}

Note. *: Means followed by the same letters within columns and main factors were not different according to Duncan's Multiple Range Test at 5\% level of significance. The root nodulation score ranged from 0 to 5 numerical scale with 0 indicating lack of root nodulation and 5 indicating maximum nodulation. These results were previously reported in Proceedings of International Lupin Conference held in Guadalajara, Mexico from September 14-18, 2005 (Bhardwaj et al., 2005).

The analysis of variance (Table 6) indicated that the alkaloid categories and bradyrhizobial strains had significant effects on root nodulation. The interaction between alkaloid categories and bradyrhizobial strains was non-significant indicating that means of alkaloid categories averaged over all bradyrhizobial strains and the means of bradyrhizobial strains averaged over all alkaloid categories could be compared.

Table 6. Analysis of variance for root nodulation in white lupin from five alkaloid categories inoculated with seven bradyrhizobial strains in the greenhouse during 2005 at Petersburg, Virginia

\begin{tabular}{ll}
\hline Source of variation & Mean squares \\
\hline Alkaloid categories & $4.92^{* *}$ \\
Bradyrhizobial strains & $14.94^{* *}$ \\
Interaction & 1.09 \\
Residual error & 0.89 \\
\hline
\end{tabular}

Note. *, **: Significant at 5 and 1\% level of significance, respectively. The root nodulation score ranged from 0 to 5 numerical scale with 0 indicating lack of root nodulation and 5 indicating maximum nodulation. 
Table 7. Root nodulation score of white lupins in five alkaloid categories inoculated with seven bradyrhizobial strains in the greenhouse during 2005 at Petersburg, Virginia

\begin{tabular}{ll}
\hline Alkaloid category & Root nodulation score \\
\hline 4 & $1.09 \mathrm{a}^{\dagger}$ \\
3 & $1.05 \mathrm{a}$ \\
0 & $0.73 \mathrm{ab}$ \\
2 & $0.54 \mathrm{~b}$ \\
1 & $0.41 \mathrm{~b}$ \\
\hline
\end{tabular}

Note. *: Means followed by the same letters within columns and main factors were not different according to Duncan's Multiple Range Test at 5\% level of significance. The root nodulation score ranged from 0 to 5 numerical scale with 0 indicating lack of root nodulation and 5 indicating maximum nodulation. These results were previously reported in Proceedings of International Lupin Conference held in Guadalajara, Mexico from September 14-18, 2005 (Bhardwaj et al., 2005).

The highest root nodulation was observed in bitter lupin lines in category 4 whereas the lowest root nodulation was observed in the relatively sweet lines in categories 1 and 2 (Table 8). It was interesting to note that root nodulation scores in lupin lines in categories 0,3 , and 4 were similar, thus, indicating that the same bradyrhizobial strain could be used to effectively inoculate white lupin lines. This observation was also supported by the lack of interaction between alkaloid categories and bradyrhizobial strains (Table 3).

Table 8. Descriptive data for 126 white lupin germplasm accessions

\begin{tabular}{llll}
\hline Variable & Dragendorff score & Oil (\%) & Protein (\%) \\
\hline $\mathrm{N}$ & 126 & 126 & 126 \\
Mean & 2.02 & 7.43 & 33.43 \\
Median & 2.00 & 7.43 & 33.09 \\
Mode & 0.00 & 9.25 & 31.38 \\
Minimum-maximum & $0-5$ & $3.70-10.35$ & $24.44-46.88$ \\
Standard deviation & 1.76 & 1.57 & 4.61 \\
Standard error of mean & 0.16 & 0.14 & 0.41 \\
$\mathrm{CV}(\%)$ & 87.39 & 21.2 & 13.78 \\
\hline
\end{tabular}

\subsection{Characterize the Variation among White Lupin Germplasm in the USDA-ARS Collection}

The white lupin germplasm had considerable variation for alkaloid content based on the Dragendorff score (Table 8). Among the 126 accessions, the Dragendorff score varied from 0 to 5 (Table 9), ten accessions had a score of 5 (Bitter), 19 accessions had a score of 4, 31 accessions had a score of 3,16 accessions had a score of 2, three accessions had a score of 1 , and 47 accessions had a score of 0 (Sweet). Significant variation existed among alkaloid categories for protein content. The ten bitter accessions, as a group, had significantly higher protein content (39.27\% dry weight basis) in comparison to the all other alkaloid categories (Table 10). The alkaloid content did not affect oil content in the seed which varied from 5.83 to $8.52 \%$ on dry weight basis).

The oil contents and Dragendorff scores ( 0.07 , non-significant correlation), and oil and protein contents $(0.09$, non-significant correlation) were not correlated. However, a correlation of +0.32 (significant at $1 \%$ level) indicated that bitter accessions had higher protein contents. 
Table 9. Classification of white lupin accessions into five alkaloid categories based on Dragendorff score and their oil and protein contents

\begin{tabular}{llll}
\hline Dragendorff score & Number of accessions & Oil (\%) & Protein (\%) \\
\hline 5 & 10 & $8.52 \mathrm{a}^{\dagger}$ & $39.27 \mathrm{a}^{\dagger}$ \\
4 & 19 & $7.53 \mathrm{a}$ & $34.46 \mathrm{~b}$ \\
3 & 31 & $7.24 \mathrm{a}$ & $33.02 \mathrm{~b}$ \\
2 & 16 & $7.04 \mathrm{a}$ & $33.37 \mathrm{~b}$ \\
1 & 3 & $5.83 \mathrm{a}$ & $31.31 \mathrm{a}$ \\
0 & 47 & $7.54 \mathrm{a}$ & $32.20 \mathrm{~b}$ \\
\hline
\end{tabular}

Note. ${ }^{\dagger}$ : Means followed by the same letters within columns and main factors were not different according to Duncan's Multiple Range Test at 5\% level of significance.

\section{Conclusions}

Characterization of alkaloid concentration in leaves, pod shells, and seed of white lupin (Lupinus albus L) indicated that a few lines had differing alkaloids in seed, leaves, and pod shells. This indicates that it may be possible to develop lupin lines with sweet or bitter seeds each combined individually with differing alkaloid content in leaves or pod shells. The significance of these results is that it may be possible to develop lupin lines that have sweet seeds for use as food or feed whereas the remaining plant tissue contains high levels of alkaloids to make it suitable to help manage insect-pests or destructive micro-organisms in the soil similar to glucosinolate-rich Brassica material. It was observed that white lupin lines with higher seed alkaloid concentrations (bitter lines) had higher root nodulation for Symbiotic N Fixation. Seed alkaloid concentration didn't affect oil concentration.

\section{References}

Aguilera, J. M., \& Trier, A. (1978). The revival of lupin. Food Technology, 32, 70-76.

Allen, J. G. (1998). Toxins and Lupinosis. In J. S. Gladstones, C. Atkins, \& J. Hamblin (Eds.), Lupins as Crop Plants: Biology, Production, and Utilization (pp. 411-435). CAB International.

Bhardwaj, H. L. (2006). Muskmelon and sweet corn production with legume cover crops. HortScience, 41(5), $1222-1225$.

Bhardwaj, H. L., Starner, D. E., Noffsinger, S. L., \& van Santen, E. (2005). Prospects of developing white lupin as an alternative crop in the mid-Atlantic region of USA. In E. van Santen \& G. D. Hill (Eds.), Mexico, Where Old and New World Lupins Meet. Proceedings of the 11th International Lupin Conference, Guadalajara, Jalisco, Mexico. May 4-5, 2005 (pp. 18-22). International Lupin Association, Canterbury, New Zealand.

Cowling, W. A., Huyghe, C., \& Swiecki, W. (1998). Lupin Breeding. In J. S. Gladstones, C. Atkins, \& J. Hamblin (Eds.), Lupins as Crop Plants: Biology, Production, and Utilization (pp. 437-454). CAB International.

Drinkwater, L. E., Wagoner, P., \& Sarraantonio, M. (1998). Legume-based cropping systems have reduced carbon and nitrogen losses. Nature, 396, 262-265. https://doi.org/10.1038/24376

Gladstones, J. S. (1998). Distribution, Origin, Taxonomy, History, and Importance. In J. S. Gladstones, C. Atkins, \& J. Hamblin (Eds.), Lupins as Crop Plants: Biology, Production, and Utilization (pp. 437-454). CAB International.

Hill, G. D. (1977). The composition and nutritive values of lupin seed. Nutrition Abstr. Rev., 47, 511-519.

Hondelmann, W. (1984). The lupin: Ancient and modern crop plant. Theor. Appl. Genet., 68, 1-9. https://doi.org/10.1007/bf00252301

Muzquiz, M., Buadrado, C., Ayet, G., De la Cuadra, C., Burbano, C., \& Osagie, A. (1994). Variation of alkaloid components of lupin seeds in 49 genotypes of Lupinus albus L. from different countries and locations. Journal of Agricultural and Food Chemistry, 42, 1447-1450. https://doi.org/10.1021/jf00043a011

Robinson, K. O., Beyene, D. A., van Berkum, P., Knight-Mason, R., \& Bhardwaj, H. L. (2000). Variability in plant-microbe interaction between Lupinus lines and Bradyrhizobium strains. Plant Science, 159, 257-264. https://doi.org/10.1016/S0168-9452(00)00345-9 
SAS. (2014). SAS for Windows version 9.4. SAS Institute, Cary, N.C. Retrieved from http://www.sas.com/en_us/ software/sas9.html

Wink, M. (1985). Metabolism of quinolizidine alkaloids in plants and cell suspension cultures. In K. H. Neumann, W. Barz, \& B. Reinhard (Eds.), Primary and Secondary Metabolism of Plant Cell Cultures (pp. 107-116). Springer, Heidelberg. https://doi.org/10.1007/978-3-642-70717-9_10

Wink, M. (1993). Biological activities and potential application of lupin alkaloids. In Martins \& da Costa (Eds.), Advances in Lupin Research (pp. 161-178). Instituto Superior de Agronomia, Technical University of Lisbon, Portugal.

Wink, M., \& Twardowski, T. (1992). Allelochemical properties of alkaloids: Effects on plants, bacteria, and protein biosynthesis. In S. J. H. Rizvi \& V. Rizvi (Eds.), Allelopathy: Basic and Applied Aspects (pp. 129-150). Chapman and Hall, London. https://doi.org/10.1007/978-94-011-2376-1_10

\section{Copyrights}

Copyright for this article is retained by the author(s), with first publication rights granted to the journal.

This is an open-access article distributed under the terms and conditions of the Creative Commons Attribution license (http://creativecommons.org/licenses/by/4.0/). 